\title{
М.В. Рубинов
}

Пермский национальный исследовательский политехнический университет

\section{ТРАНСПОРТНЫЕ ПРОБЛЕМЫ ГОРОДОВ: РОЛЬ ТРАДИЦИЙ, СОЦИАЛЬНАЯ ИНЖЕНЕРИЯ И ИНСТИТУЦИОНАЛЬНЫЕ ИЗМЕНЕНИЯ}

\begin{abstract}
Рассмотрены критерии для выбора теоретических подходов к изучению городов как особых социальных явлений. В соответствии с этими критериями выбраны взаимодополняющие теоретические подходы для изучения проблем городов при предоставлении общественных благ, в том числе в сфере городского транспорта. В применяемых подходах обращается особое внимание на роль предпринимательского процесса при решении данных проблем. Выбранные теоретические подходы в сочетании со сравнительно-историческим методом используются для выявления барьеров, препятствующих решению современных проблем городского транспорта, и для выработки принципов, в соответствии с которыми проблемы в данной сфере должны устраняться.

Ключевые слова: городской транспорт, общественные блага, согласование интересов, предпринимательство, традиции, социальная инженерия, институциональные изменения.
\end{abstract}

Как отмечает Ф.А. Хайек, и понятие «город», и другие понятия общественных наук относятся к понятиям, которые «невозможно определить в физических терминах и которые отсылают нас к некому комплексу отношений, каковые, будучи выражены в явном виде, и составят ,,теорию’ данного предмета». По словам этого мыслителя, явления, которые характеризуются такими понятиями, «мы никогда не наблюдаем ...как целое. Когда мы пользуемся любым из этих понятий, за ним всегда обнаруживается схема, соединяющая индивидуальные действия осмысленными для нас отношениями; другими словами, мы пользуемся теорией, которая говорит нам, что является и что не является частью нашего предмета». Таким образом, для изучения проблем городов необходима теория, или «мыслительная схема для интерпретации». Согласно Хайеку, теория может быть неприемлемой для исследо- 
вания определенных социальных явлений в силу ряда причин. Она может быть противоречивой. «Она может не иметь отношения к делу, поскольку упоминаемые в ней условия никогда не встречаются; или она может быть неадекватной, поскольку не учитывает достаточно болышого количества условий» [1, с. 86-89]. Вероятно, теоретические подходы Д. Джекобс к проблемам городов получили признание как раз в силу того, что являются в значительной степени непротиворечивыми и учитывают условия, которые необходимо принимать во внимание при исследовании этих проблем.

По утверждению Д. Джекобс, «когда перед экономикой встает новая серьезная проблема, решить ее можно только за счет создания новых товаров и услуг». Для создания новых товаров и услуг необходимы идеи и материальные ресурсы, то есть те товары и услуги, которые уже производятся и подходят для реализации этих идей. Далеко не все идеи могут оказаться удачными: требуется опробовать различные варианты, предполагающие использование различных ресурсов. От древности до наших дней условия для таких действий существуют только в больших городах, поскольку именно в них на компактной территории сосредоточены различные виды деятельности [2, c. $90,131,137,141-144]$.

Обладая этими преимуществами, большие города сталкивались в прошлом и сталкиваются в настоящее время с проблемами в сфере предоставления благоприятных условий для жизни. Такие условия часто называют общественными благами. По причине размещения значительного населения людей на ограниченной территории проблемы больших городов при предоставлении общественных благ отличались и отличаются большей остротой по сравнению с городами меньшего размера и сельскими поселениями. Среди этих проблем следует назвать и эпидемии, которые не стали достоянием прошлого. Д. Джекобс обращает внимание на такие проблемы американских городов 2-й половины XX в., как переполнение улиц автомобильным транспортом и загрязнение воздуха выхлопами этого вида транспорта [2, с. 142- 
143]. Данные трудности остаются актуальными и в настоящее время, причем не только для американских городов.

Хотя перечень проблем больших городов на этом не исчерпывается, есть основания выделить из этих проблем транспортную сферу больших городов и городских агломераций. Скорость перемещения по городским магистралям и качество городского воздуха являются общественными благами, без предоставления которых развитие города развиваться не могут. От состояния городского транспорта, и, в частности, от размеров индивидуального пространства, которое городской транспорт предоставляет пассажирам [3, с. 373], во многом зависит способность городов противостоять эпидемиям.Вероятно, индивидуальное пространство в маршрутном транспорте является особенно ценным для горожан, более других склонных к созданию новых товаров и услуг [4, с. 132-133]. Таким образом, в транспортной сфере городов остро проявляются как проблема согласования интересов различных групп потребителей, так и проблема согласования частных и общественных интересов. Может оказаться, что решение данных проблем в сфере транспорта поможет преодолению трудностей, связанных с предоставлением других общественных благ в условиях города.

Д. Джекобс доказывает, что большие города способны преодолевать препятствия в сфере предоставления общественных благ. Это происходит именно благодаря внедрению новых технологий, которые могут возникнуть только в больших городах. Такие технологии в дальнейшем позволяют сделать более «пригодными для жизни» и населенные пункты меньших размеров. Однако появление новых технологий нередко наталкивается на барьеры, возникающие вследствие особенностей устройства того или иного общества, или, иначе говоря, на барьеры в виде определенных общественных институтов. По словам Джекобс, «когда одним группам участников экономической деятельности позволено решать проблемы практического характера, а другим нет, то предлагаемые решения этих проблем оказываются удивитель- 
но однобокими, при этом проблемы продолжают непрерывно накапливаться» $[2$, c. 144$]$.

Если использовать определение социализма, которое сформулировал экономист Х. Уэрта де Сото, то барьеры, о которых говорит Д. Джекобс, следует считать одной из «систем институциональной агрессии (вмешательства) против свободы человеческой деятельности или предпринимательства». Х. Уэрта де Сото называет агрессию «институциональной», то есть она должна осуществляться с помощью определенных общественных институтов. Под институтами данный автор понимает «любой повторяющийся паттерн, норму или модель поведения, вне зависимости от того, к какой сфере они относится: лингвистической, экономической, правовой и т.п.». Х. Уэрта де Сото считает социализмом любую из таких систем [5, с. 29, 80-81].

Преграды на пути предпринимательства с соответствующим накоплением проблем, можно обнаружить и в транспортных системах различных городов. Отсутствие легальных возможностей для удовлетворения спроса на перевозки приводит к «прорехам в формальной транспортной системе» и способствует появлению различных форм теневой экономики в сфере транспорта. Такая ситуация была характерна для Перу 1920-х-1980-х гг., где «официальное признание перевозчиков рассматривалось не как право, а как привилегия, допускаемая в обмен на принятие политического вмешательства и многочисленных тягот, включая контроль платы за проезд». При этом, «одной из многих привилегий, полученных в обмен на подчинение правительственному контролю, было ослабление требований к безопасности со стороны властей» [6, с. 130-131]. В 1980-е гг. данное положение дел перуанские экономисты и в значительной степени массы признали неприемлемым, и была начата работа по созданию правовой системы, которая обеспечивала бы участие множества предпринимателей в осуществлении городских пассажирских перевозок при соблюдении общественных интересов, прежде всего, заключающихся в обеспечении стандартов безопасности [6, с. 281-282]. В 1990-е гг. предприниматели осуществляли нелегальные перевозки маршрут- 
ными такси в Нью-Йорке. Эти перевозки пользовались большим спросом у горожан, недовольных услугами легального общественного транспорта [7, с. 366-367]. С нелегальными перевозчиками в сфере пассажирского транспорта боролось и министерство транспорта Пермского края [8, с. 147-148].

Власти Сингапура с 1960-х гг. стали проводить политику, направленную на ограничение использования личных автомобилей, за счет которых во многом происходило переполнение улиц автомобильным транспортом. Правительство города-государства принимало меры по развитию массового маршрутного транспорта. Реализация этих мер получила высокую оценку со стороны таких авторов, как эксперт в сфере городского транспорта В. Вучик и журналист Ю. Сигов [3, с. 307-308, 498-499; 9, с. 45]. Переполнение улиц автомобильным транспортом в значительной степени сдержать удалось, однако можно найти свидетельства, что услуги массового маршрутного транспорта не вполне соответствуют требованиям, по меньшей мере, части потребителей - таких потребителей, которые нуждаются в более качественных услугах. Подобная ситуация может быть одним из источников социальных проблем, существенных для Сингапура [4, с. 132-133]. Не является ли неудовлетворенность части потребителей, хотя и выражающаяся в косвенных формах, признаком того, что при решении проблем массового маршрутного транспорта правительство Сингапура брало на себя предпринимательские функции?

Демонтаж барьеров, которые препятствуют решению проблем городов, требуется обосновать. Необходимо объяснить, в силу каких причин барьеры, не допускающие определенным участников к важнейшим сферам городской экономической деятельности, и в прошлом, и в современных городах, ведут к стагнации. Чтобы использовать опыт прошлого для решения современных проблем, необходимо классифицировать данные барьеры и выявить связь между барьером определенного вида и стагнацией в городах, а, следовательно, и в обществах, где функционируют эти города. В исследованиях Д. Джекобс говорится о барьерах, которые можно разделить на три вида: традиции, 
связанные с представлениями о престижности или непрестижности определенного вида деятельности; действия лиц и групп, направленные на противодействие конкуренции; ошибочные концепции, выдвинутые экспертами и получившие поддержку со стороны руководителей городов и государств.

Барьеры третьего вида часто сводятся к такому подходу, который Х. Уэрта де Сото социальной инженерией или сциентистским социализмом. Данный подход обращает внимание «исключительно на конечные состояния равновесия и зависит от самонадеянного предположения о том, что вся необходимая информация дана ученому и доступна ему...» [5, с. 165]. Примером такого подхода являются взгляды городских проектировщиков, утверждавших, что «нужды данного участка в товарах можно подсчитать научно», a, следовательно, торговле должно отводиться «столько-то места и не больше» [10, с. 34] . Еще одним примером такого подхода является увеличение пропускной способности городских магистралей путем их расширения в ущерб другим городским объектам, необходимым для поддержания процессов обмена знаниями, товарами и услугами [10, с. 37; 2, с. 140]. Если использовать терминологию Х. Уэрта де Сото, то возникают преграды на пути потоков «практической информации, которую люди постоянно порождают и передают друг другу в ходе социального процесса» [5, с. 165]. Когда эти процессы обмена затруднены, городам угрожает упадок: «Если обычные люди, занимающиеся рутинной работой, не пытаются решить проблемы, никто другой не в состоянии это сделать за них» [2, с. 145].

Взглядам Д. Джекобс не противоречит «реально осуществимое совершенствование» социальных институтов, которое признает необходимым Ф.А. Хайек. В случае такого реформирования «главным является экспериментальная попытка улучшить функционирование отдельных частей при невозможности полного понимания структуры в целом». Более совершенный порядок должен в большей мере предоставлять «долгосрочные возможности, открываемые различными правилами разным членам общества» [11, с. 108, 543]. 
Д. Джекобс приводит примеры, показывающие, каким образом определенные традиции препятствовали развитию городов. Так в Древнем Риме, «рабы-водоносы... составляли самую низшую категорию городских тружеников... Сами рабы не могли свободно совершенствовать свой труд, возводя водопроводные сети, и даже не могли пытаться это сделать» [2, с. 145]. В современных городах, когда речь идет о массовом маршрутном транспорте, традиционные представления тесно переплетаются с концепциями, которые можно оспорить, опираясь на подходы Дж. Джекобс и Х. Уэрта де Сото.

Существует достаточно распространенное мнение, что маршрутный транспорт следует считать «уделом неудачников и оригиналов», неспособных приобрести автомобиль либо управлять им [3, с. 10]. К этому мнению довольно близка точка зрения «значительной части американских экспертовтранспортников... согласно которой общественный транспорт является в первую очередь специфическим социальным сервисом, рассчитанным на пожилых и маломобильных горожан». С таким мнением решительно не согласен В. Вучик, однако он настаивает на субсидировании транспортных тарифов государством «по причине динамичного влияния индивидуальных поездок на функционирование и жизнеспособность города». Можно сказать, что и В. Вучик рассматривает массовый маршрутный транспорт как «социальный сервис», хотя и предназначенный для большинства горожан. При этом государство и муниципалитеты должны планировать не только улично-дорожную сеть и пешеходные зоны, но и деятельность различных видов массового маршрутного транспорта [3, с. 197, 373]. Если осуществляется планирование деятельности маршрутного транспорта, то органы власти вправе определять различные стороны этой деятельности: направления и протяженность маршрутов, величину тарифов, интервалы движения, уровень безопасности и комфортабельности транспортных средств. Если транспортные услуги субсидируются и осуществляются согласно планам, утвержденным органами власти, то потребители могут добиться повышения их качества только путем воздействия на эти органы. При этом разные группы потребителей выдвигают раз- 
личные требования к качеству и даже к уровню безопасности транспортных услуг. Но даже если правительственный орган решит выполнить запросы наиболее требовательных пассажиров, то этот орган не сможет решить «фундаментальную проблему неустранимого неведения» [5, с. 106, 131, 156-157], в данном случае применительно к запросам пассажиров и к способам удовлетворения этих запросов. В сфере транспорта, как и в других сферах экономической деятельности, применение компьютеров не откроет правительственным органам доступ к сведениям, которые в состоянии получить только предприниматели, поскольку «компьютерные системы способны исключительно на то, чтобы применять открытую ранее информацию к конкретнымм ситуациям; они в принципе не в состоянии создать новую информацию в отношении тех ситуаций, которые еще не были обнаружены... » [5, с. 124].

Характерно, что В.Вучик и М.Блинкин, видный российский транспортный эксперт, редактировавший перевод работы В.Вучика, негативно относятся к дерегулированию деятельности маршрутного транспорта: то есть к предоставлению владельцам транспортных средств права самим определять маршруты, расписания и тарифы. В качестве обоснования для такой точки зрения приводится неудачный, по мнению данных авторов, британский опыт частичного дерегулирования 1980-1990-х гг., которое, правда, не сопровождалось мерами по ограничению использования личных автомобилей. Негативно оценивается и российский опыт частного предпринимательства 1990начала 2000-х гг. в сфере городских пассажирских перевозок. Тем не менее, В. Вучик признает, что «частные перевозчики предлагали горожанам «транспортные услуги хотя и невысокого качества, но по весьма гибким схемам и приемлемым тарифам». Сравнение качества услуг, предоставляемых частными перевозчиками, и услуг муниципальных перевозчиков в этот период, по всем существенным критериям, в частности, по таким критериям, как безопасность, наличие свободных посадочных мест, требует специального рассмотрения. Исследование недавнего прошлого транспортной системы будет полезным для оценки той транспортной политики, которая проводится в го- 
родах России в настоящее время. Весьма настороженно данные авторы относятся и к такому виду транспорта, как маршрутные такси, поскольку в этот сегмент проще всего проникнуть «мелкому частному бизнесу», причем контроль над расписаниями и тарифами в данном случае более сложен [3, с. 4041, 202-203, 288-297, 399, 438].

В концепции Д.Джекобс, можно найти положения, направленные против тех ограничений экономической активности в сфере массового маршрутного транспорта, на которых настаивают В.Вучик и М.Блинкин. По утверждению Джекобс, «какими бы целями ни оправдывались попытки удержать экономическую активность в жестких рамках привычных категорий - будь то потребности планирования, зонирования, интересы цеховых корпораций, ассоциаций или профсоюзов, - они препятствуют появлению новых видов экономической деятельности». При этом «крупные экономические организации» менее склонны дополнять старые виды деятельности новыми [2, с. 102, 107 , 110-112, 116-118]. Появление новых видов деятельности важно и в сегменте массового маршрутного транспорта, поскольку в этой сфере существуют давние проблемы, или появляются новые, или вновь возникают проблемы, которые ранее считались решенными. Характерно, что первые трамваи, которые как вид городского транспорта высоко оценивает В.Вучик, появились не по инициативе городских властей [4, с. 128-129]. В настоящее время без привлечения дополнительных транспортных средств, предоставляемых частными предпринимателями, невозможно обеспечить пространство для каждого из пассажиров, необходимое для долгосрочного противодействия эпидемическим угрозам. Запрет на участие малого бизнеса в предоставлении транспортных услуг можно сравнить с «искусственно поддерживаемым» разделением торговли и ремесел, которое существовало с древнейших времен в Индии и в средневековой Шотландии, что отрицательно сказывалось на экономическом развитии городов в этих странах, a, следовательно, и на экономическом развитии самих стран [2, с. 173]. 
Таким образом, институциональные изменения в транспортных системах городов и городских агломераций должны быть направлены на предоставление максимально широких возможностей для предпринимательской деятельности в данных системах. При этом предпринимательство должно осуществляться в рамках ограничений, продиктованных точно сформулированными общественными интересами. Удовлетворение общественных интересов обеспечивается в том случае, если максимально доступны общественные блага, связанные с деятельностью городского транспорта. Но эти блага могут быть доступны в наибольшей степени только в тех условиях, когда у предпринимателей есть максимальные возможности производить услуги и товары, направленные на решение транспортных проблем.

\section{Список литературы}

1. Хайек Ф.А. Факты общественных наук / пер. с англ. О.А. Дмитриевой под ред. Р.И. Капелюшниковой // Хайек Ф.А. Индивидуализм и экономический порядок. - Челябинск: Социум, 2011. - С. 69-92.

2. Джекобс Дж. Экономика городов / пер. с англ. под общ. ред. О. Н. Лугового. - Новосибирск: Культурное наследие, 2008. - 294 с.

3. Вучик В.Р. Транспорт в городах, удобных для жизни / пер. с англ. А. Калинина под научн. ред. М. Блинкина. - М.: Издательский дом «Территория будущего», 2011. - 576 с.

4. Рубинов М.В. Развитие городского транспорта, предпринимательская инициатива и долгосрочная аренда // Современный город: власть, управление, экономика: сб. науч. ст. - Пермь: Изд-воПерм. нац. исслед. политехн. ун-та, 2019. - Вып.ІХ. - С. 127-137.

5. Уэрта де Сото X. Социализм, экономический расчет и предпринимательская функция / пер. с англ. В. Кошкина под ред. А. Куряева. - М., Челябинск: ИРИСЭН, Социум, 2008. - 488 с. 
6. Сото Э. де. Иной путь. Экономический ответ терроризму / пер. с англ. Б. Пинскера. -Челябинск: Социум, 2016. - 400 с.

7. Мэнкью Г. Н. Принципы микроэкономики / пер. с англ. В. Кузин. - СПб.: Питер, 2003. - 560 с.

8. Шилов Ю.Г., Белоногов Ю.Г. Проблемы организации межмуниципальных автобусных маршрутов в Пермской агломерации // Современный город: власть, управление, экономика: сб. науч. ст. - Пермь: Изд-во Перм. нац. исслед. политехн. ун-та, 2019. - Вып. IX. - С. 138-148.

9. Сигов Ю. Сингапур: Восьмое чудо света. - М.: Альпина нонфикшн, 2015. - 334 c.

10. Джекобс Д. Смерть и жизнь больших американских городов; пер. с англ. - М.: Новое издательство, 2011. - 460 с.

11. Хайек Ф.А. фон. Право, законодательство и свобода: Современное понимание либеральных принципов справедливости и политики/ пер. с англ. Б. Пинскера и А. Кустарева под ред. А. Куряева. - М.:ИРИСЭН, 2006. $644 \mathrm{c}$.

\section{M.V. Rubinov}

Perm State National Research University

\section{URBAN TRAFFIC PROBLEMS: THE CONTRIBUTION OF TRADITIONS,SOCIAL ENGINEERING AND INSTITUTIONAL CHANGES}

Urban studies need theoretical approaches. The article reviewed criteria for such approaches' selection. Selected approaches greatly emphasize the entrepreneurship contribution to public goods' provision, specifically, in the field of urban traffic. The barriers for solving of urban traffic problems were identified due to these approaches supplemented supplies with comparative historical method. The principles of such problems' solving were offered.

Keywords: urban traffic, public goods, accommodation of interests, entrepreneurship, traditions, social engineering, institutional changes. 